\title{
Driving smart cities through smart projects
}

\author{
Mauro Romanelli 10000-0002-5909-8423] \\ ${ }^{1}$ University of Naples Parthenope, Naples, Italy \\ mauro.romanelliduniparthenope.it
}

\begin{abstract}
Cities are rethinking how to drive future urban development following a smart vision to urban growth in order to improve the quality of life of citizens. As adopting a smart approach to urban development, cities are investing in the design and implementation of smart city projects to transform in a significant way the urban community, and to enhance social and economic performances of a city. By Investing in smart city projects, cities identify a sustainability-oriented pathway addressing and developing smart and intelligent solutions to urban problems, relying on information technology as a source that enables cities to develop innovation processes and drive sustainable urban growth. Cities are adopting a smart vision by promoting smart city projects that help encourage cooperation and support a collaborative framework to drive innovation in services and knowledge for sustainable urban development. Smart city projects are increasing, but the pathway leading to smart and sustainable development is still in the initial stage. Smart city projects emerge as a necessary step to support collective learning processes that enable urban change and innovation coherently with a long-term horizon.
\end{abstract}

Keywords: smart city, urban sustainability, smart city projects.

\section{Introduction}

The future development of cities as communities relies on cities rethinking a smart vision for urban change and growth as a source that enables the city to advance towards urban sustainability and improve the quality of life of people living within urban communities. In particular, following a smart city vision implies that cities must adopt, develop and implement smart city projects in order to undertake an effective and substantial transition of the city towards a smart-driven or smart city to enhance social and economic performances of a city.

Smart city-based development is emerging as a potential model for cities aiming to support social and economic growth within information and knowledge era [1]. It is no simple task to make a city as smart city without rethinking how to plan and rethink the stages of evolution. Following the monitoring of several steps relies on defining a project that opens up to goals, sources, times and organisational action to drive the city towards change, embracing a smart vision leading to urban sustainable development. 
Cities invest in smart city initiatives and vision to improve the quality of life encompassing socio-environmental aspects and information and technology applications [2].

While the need to embrace a smart approach to urban development of cities is an aspect well documented in the literature about smart cities, there are few studies that elucidate the role of smart city projects within a smart city model which includes social, economic, urban, institutional, technological and environmental aspects [3].

The aim of this study is to elucidate the role of smart city projects as a means that helps cities to become smart, by viewing the smartness as a vision to support urban, social and economic growth. In particular, smart evolutions and solutions help cities improve technological infrastructures in order to make effective the bridge between social, urban and technological frameworks [4].

Cities are rethinking a smart-oriented approach to face the problems of rapid urbanisation [5]. Smart cities emerge as a conceptual development model that relies on using information technology to improve human capital and increase urban sustainability and future [6], enabling the optimisation of all city functions [7]. The advantages of a smart city approach concern: benefits to urban transportation and mobility, access to city resources, opportunities for the employment and support to local growth [4].

Smart cities projects and vision help to construct a people-centred approach to urban governance in order to develop jointly economic growth, social sustainability and cohesion [8,9]. Building smart cities relies on promoting urban governance that enhances the relationships between bottom-up initiatives and city strategy, bringing together human collaboration and technological systems to transform urban spaces, making effective diverse public values coherently with specific context [8].

As drivers of economic and social growth, and multi-level cooperation-led innovation [10], cities aim to proceed towards sustainable development by using information and digital technology to support urban growth, knowledge and innovation-led economy $[11,12]$ and improve the living conditions for citizens [13].

As following a smart approach and vision to urban development, cities design a pathway for sustainability and learn how to define and design organisational processes and infrastructures that drive cities to evolve as smart-driven inclusive urban communities [14, 15]. Smart city initiatives rely on using emerging technologies and help exploring future scenarios of contemporary cities [16].

Thereby, leading cities towards a long term urban development implies to understand how cities can define and implement a smart city project as an effective urban management model for urban growth [1].

Designing cities of the future relies on developing a smart approach to strengthen social and public value creation, social inclusion, and innovation to drive urban development over time. Cities as smart communities understand the potential of information technology, designing and implementing smart city projects [3].

The paper is structured in the following way. After introduction, understanding smart and sustainable cities for driving urban development is presented in the second section. In the third section, smart city projects and strategies are considered as means to drive cities into urban future. Finally, conclusions are outlined. 


\section{Understanding the role of smart cities as drivers of sustainable urban development}

Cities are embracing a smart vision to rethink and plan urban futures and spaces by embracing information technology to redesign a smart city urban planning. Cities promote smartness as a vision that enables the city to modernize urban services and infrastructures by employing information communication technologies (ICTs) in urban economy, services, life and society. «Smart City is furthermore used to discuss the use of modern technology in everyday urban life» (p. 10) [17].

Hence, technology is one of the conditions for cities becoming smart. There is no one route for achieving this. Several approaches emerge because a smart city strategy refers to local aspects in terms of governance models, local culture and the citizens' involvement [18]. In particular, cities promote smartness as a vision for change that makes the city a smart community [19].

Smart city is a multidimensional and socio-technical phenomenon that relies on technology, management and policy components in a comprehensive way [5]. GilGarcia, Pardo and Nam [20] state that «a smart city should be seen as a continuum in which local government officials, citizens, and other stakeholders could think about the initiatives that attempt to make the city a better place to live» (p. 5). As a conceptual development model, a smart city helps enhance the city's human, collective, and technological capital for increasing urban sustainability [6].

Cities adopt a smart strategy to address urban development «for improving the operational and managerial efficiency and the quality of life by building on advances in ICTs and infrastructures» (p. 186) [21]. Cities invest in smart solutions to contribute to a high quality of life and to achieve sustainable development in urban spaces in terms of efficient use of resources, competitive knowledge and innovationled economy [12]. Community, technology and policy drive smart city and enable productivity, sustainability, accessibility, wellbeing, liveability and governance [22].

Sustainability is an opportunity that requires invention, it is a process that involves a self-conscious choice [23]. Smartness is considered as a source to drive cities to become sustainable. While a smart city helps to improve services through technology with regards to human side of change, sustainable city relies on decision-making processes to improve urban community following a future-oriented and long time horizon [24]. Sustainability-oriented cities adopt a smart vision that relies on using information and digital technology as a source to support urban future, knowledge and innovation economy [11]. As drivers of economic and social growth fostering innovation and encouraging multi-level public-private partnerships, [10], cities develop knowledge-based strategies to drive sustainable urban development [25].

Smarter cities enhance values as innovation and cohesion developing governance and community [26], matching technologies, tools and applications with urban functions and contexts [27].

Technology helps to improve urban quality of life for sustainable development [12], and drive urban innovation in management, governance and policy [28], leading to modernisation and automation of urban spaces [15]. In particular, cities invest in innovation, linking technology and knowledge with people and territory to drive 
urban development [29]. Technology also provides a platform for collaboration and a symbol that provides community value to share new ideas, resources and projects [30].

The adoption of smart urban technologies helps cities to become a smart city by ensuring both technological excellence and economic competitiveness as a means to promote urban society and support urban growth and development [1]. Cities adopt a smart approach to build collaborative processes between people, business and government within community for urban and open innovation enabling an inclusive city and empowering the role of citizens in shaping urban smartness and change [29]. Smart cities contribute to urban innovation involving all the stakeholders of urban environment. Cities select a smart approach using the potential of information technology in order to enhance economy, governance, people, mobility, environment and living to drive urban sustainable growth and ensure a high quality of life leading systems, service and capabilities in an organic network [30].

\section{Driving cities into the future through smart city projects and strategies}

Cities becoming smart plan investments in human and social capital for ensuring high quality of life by developing new communication infrastructures for sustainable economic growth and participatory governance [31].

It is difficult to rethink about the city as a smart community without planning a smart city project and strategy to drive the city towards future urban development. Driving smart and sustainable urban change requires long-term processes and mindset [3] and relies on a roadmap coherently with particular city context, needs, and local interests [13].

Investing in smart city projects helps transform the urban community in a significant and positive way [32]. Smart city projects help cities to identify a pathway for building sustainable, learning and inclusive cities meeting the expectations of urban society in 21 th century [33]. Smart city projects provide the potential to advance the progression towards smart, sustainable and inclusive growth, enabling the creation of more sustainable cities [34].

As real challenges that influence the development of cities [7], smart city projects help design an integrated city of the future, stressing the relevance of both technological and collaborative dimensions that enhance the relationships among urban stakeholders as a means that enables the city to become smarter [3].

Smart city projects help cities to identify both a comprehensive strategic plan and sustainable pathway for urban growth [35]. Smart city projects enable cities to develop human-centred pathways by using technology to involve stakeholders to engage in collaborative and participatory processes for engendering urban innovation [36]. Technology helps cities to design projects that support urban renewal and change. Smart cities encourage user-driven innovation projects by using technology for stimulating open and collaborative innovation [37]. Smart city projects help the 
diffusion of a culture of smartness as support to the creation and development of knowledge management processes in enterprises [38].

Designing a smart city strategy relies on sustaining connectivity platforms. Following a socio-technical framework, smart city projects are considered in terms of both technological and instrumental values, collaborative and symbolic value. Smart city projects enable urban collaboration design and legitimize innovative solutions leading cities to facing uncertainty and complexity of urban problems [39].

A smart city strategy is an important urban development policy which has an impact in services delivery and relationships among the public sector, citizens and businesses, shaping the future of society and governance. A smart city strategy relies on promoting technological infrastructure development using technology to ensure both efficient function and develop innovative solutions in order to improve urban quality of life [6].

The quality of life of citizens is the issue of cities becoming smart. Planning smart cities development relies on bridging technological advancements, knowledge and innovation networks to realize an effective digital and human intelligence-driven smart city [11]. The role of smart city strategies is to enhance information technology to support a bottom-up vision, to improve citizen awareness and provide privacy and security issues [40]. Driving smart city projects helps develop urban innovation as innovative practices to improve urban environments [39]. By implementing smart city projects, cities become smarter upgrading the elements related to techno-economic activity, the environ-urban configurations and the socio-institutional structure, enhancing the relationships between public and private actors to support urban innovation ecosystems [3]

Developing smart city projects relies on building a smart city ecosystem that enhances cooperation breeding entrepreneurial opportunities [41]. Successful smart city projects rely on considering citizens as key stakeholders that provide inputs for urban development and growth [42]. Smart city projects make cities as smart and inclusive communities where citizens promote innovations and technological advancements, by improving their local communities and fostering community entrepreneurship [14]. Smart city initiatives contribute to placing human values within community to strengthen economic growth regeneration, inclusivity and opportunities for change [43].

\section{Discussion and Conclusions}

Investing in smart city projects and strategies relates to identifying a long-term horizon for urban change. Promoting smart city projects helps to develop debate and dialogue within city as a community in order to identify possible trajectories of development to address strategic and social urban growth.

Driving cities to identify and develop a pathway for building the city as more smart and sustainable community is a long term goal that relies on promoting and implementing smart city projects as a source and means to support urban innovation, modernisation and growth. 
Cities are sustaining relevant efforts to modernize urban spaces and environments in order to improve the quality of life for citizens. The orientation to smart city projects is advancing even if a smart strategy design seems to be still at infancy age. In particular, rethinking smart city projects following a top-down and techno-centric approach fails to help social and economic urban growth, while a smart city projects is to emerge as an opportunity to support urban intelligence and construct a sustainable-oriented pathway that relies on a participatory and collaborative-oriented framework that fosters the relationships between city governments and urban stakeholders involved in defining and implementing smart city projects' issues.

There are social, managerial and organisational implications. Developing smart city projects relies on involving the urban community in the definition, acceptance, design and implementation of the project. All the urban stakeholders have to develop adequate managerial capabilities to govern the process of project management. Cities emerge as collaborative spaces that enable the generation of ideas and projects that contribute to better quality of life of people and businesses within urban community. Smart city as a model of urban development is a global trend with local peculiarities in effective realisation. Following a smart approach helps cities to redesign urban planning and select a strategic pathway and long-term horizon to realize effectively liveable urban environments that enable economic and productive activities, and facilitate the improvement of urban quality of life. The urban landscape is emerging as an interesting workshop where cities are experimenting new ways to develop urban innovation in services and functionalities.

There are some limitations in the study. Smart solutions and approach are viewed as a driver of urban growth and development. There is not a comparison among different urban realities. The study is mainly descriptive and sheds lights on efforts of cities planning a smart-driven urban future. Further research investigations would focus on a comparison among more countries about how smart city projects are planned, designed and implemented in different urban environments.

\section{References}

1. Yigitcanlar, T: Smart cities: an effective urban development and management model? Australian Planner, 52(1), 27-34 (2015)

2. Neirotti, P., De Marco, A., Cagliano, A.C., Mangano, G., Scorrano, F.: Current trends in Smart City initiatives: Some stylised facts. Cities, 38, 25-36 (2014)

3. Camboin, G.F., Zawiskak, P.A., Pufal, N.A.: Driving elements to make cities smarter: Evidences from European projects. Technological Forecasting \& Social Change, 142, 154167 (2019)

4. Bătăgan, L.: The use of Intelligent Solutions in Romanian Cities. Informatica Economică, 16(4), 37-43 (2012)

5. Gil-Garcia, J.R., Pardo, T.A., Nam, T.: What make a city smart? Identifying core components and proposing an integrative and comprehensive conceptualization. Information Polity, 20(1), 61-87 (2015)

6. Angelidou, M.: Four European Smart City Strategies. International Journal of Social Sciences Studies, 4(4), 18-30 (2016)

7. Baltac, V.: Smart Cities - A View of Societal Aspects. Smart Cities, 2, 538-548 (2019) 
8. Meijer, A.J., Gil-Garcia, J.R., Bolívar, M.P.R.: Smart City Research: Contextual Conditions, Governance Models, and Public Value Assessment. Social Science Computer Review, 34(6), 647-656 (2016)

9. Murphy, P.: Urban governance for more sustainable cities. European Environment, 10(5), 239-246 (2000)

10. European Commission: Report from the Commission to the Council on the Urban Agenda for the EU, COM(2017) 657 final, 20.11.2017 (2017)

11. Angelidou, M.: Smart cities: A conjuncture of four forces. Cities, 47, 95-106 (2015)

12. Bătăgan, L.: Smart Cities and Sustainability Models. Informatica Economică, 15(3), 80-87 (2011)

13. Ibrahim, M., El-Zaart, A., \& Adams, C.: Smart sustainable cities roadmap: Readiness for transformation towards urban sustainability. Sustainable cities and society, 37, 530-540 (2018)

14. Kummitha, R.K.R., Crutzen, N.: How do we understand smart cities? An evolutionary perspective. Cities, 67, 43-52 (2017)

15. Ahad, M.A., Paiva, S., Tripathi, G., Feroz, N.: Enabling technologies and sustainable smart cities. Sustainable Cities and Society, 61, 102301 (2020)

16. Andreani, S., Kalchschmidt, M., Pinto, R., Sayegh, A.: Reframing technologically enhanced urban scenarios: A design research model towards human centered smart cities. Technological Forecasting \& Social Change, 142, 15-25 (2019)

17. Giffinger, R., Fertner, C., Kramar, H., Kalasek, R., Pilchler-Milanović, N., Meijers, E.: Smart Cities: Ranking of European Medium-Sized Cities. Vienna, Austria: Centre Centre of Regional Science (SRF), Vienna University of Technology. Available from http://www.smart-cities.eu/download/smart_cities_final_report.pdf.

18. Dameri, R.P., Benevolo, C., Veglianti, E., Li, Y.: Understanding smart cities as a glocal strategy: A comparison between Italy and China. Technological Forecasting \& Social Change, 142, 26-41 (2019)

19. Deakin, M.: Smart cities: state-of-the-art and governance challenge, Triple Helix, 1(7), 1-16 (2014)

20. Gil-Garcia, J.R, Pardo, T.A., Nam, T.: A Comprehensive View of the 21 Century City: Smartness as Technologies and Innovation in Urban Contexts. In J.R. Gil-Garcia et al., Smarter as the New Urban Agenda. A Comprehensive View of the $21^{\text {st }}$ Century, City (pp. 121), Public Administration and Information Technology, Springer, Cham (2016)

21. Nam, T., Pardo, T.A.: Smart city as urban innovation with dimensions of technology, people and institutions. In Proceedings of the $5^{\text {th }}$ international conference on theory and practice of electronic governance(pp. 185-194). ACM (2011)

22. Yigitcanlar, T., Kamruzzaman, M., Buys, L., Ioppolo, G., Sabatini-Marques, J., Moreira da Costa, E., Yun, J.J. (2018). Understanding 'smart cities': Intertwining development drivers with desired outcomes in a multidimensional framework. Cities, 81, 145-160 (2018)

23. Alberti, M., Susskind, L.: Managing urban sustainability. An introduction to the. Environ impact assess rev, 16, 213-221 (1996)

24. D’Auria, A., Tregua, M., Vallejo-Martos, M.C.: Modern Conceptions of Cities as Smart and Sustainable and Their Commonalities. Sustainability, 10(8), 1-18 (2019)

25. Knight, R.V.: Knowledge-based Development: Policy and Planning Implications for Cities. Urban Studies, 32(2), 225-260 (1995)

26. Allwinkle, S., Cruickshank, P.: Creating smart-er cities: An overview. Journal of urban technology, 18(2), 1-16 (2011)

27. Stratigea, A., Papadopoulou, C.-A., Panagiotopoulou, M.: Tools and Technologies for Planning the Development of Smart Cities. Journal of Urban Technology, 22(2), 43-62 (2015) 
28. Nam, T., Pardo, T.A.: Conceptualizing smart city with dimensions of technology, people and institutions. In Proceedings of the $12^{\text {th }}$ annual international digital government research conference: digital government innovation in challenging times(pp. 282-291). ACM (2011)

29. Paskaleva, K.A.: The smart city: A nexus for open innovation? Intelligent Buildings International, 3(3), 153-171 (2011)

30. Albino, V., Berardi, U., Dangelico, R.M.: Smart cities: Definitions, dimensions, performance, and initiatives. Journal of Urban Technology, 22(1), 3-21 (2015)

31. Caragliu, A., Del Bo, C., Nijkamp, P.: Smart cities in Europe. Journal of Urban Technology, 8(2), 65-82 (2011)

32.Eger, J.M.: Smart communities, universities, and globalization: Educating the workforce for tomorrow's economy, Metropolitan Universities, 16(4), 28-38 (2005)

33. Osborne, M., Kearns, P., Yang, J.: Learning cities: Developing inclusive, prosperous and sustainable urban communities. International Review of Education, 59(4), 409-423 (2013)

34. Deakin, M., Hirst, P., Hummerstone, E., Webb, S., Karlsson, Ann-Kristin, Blin A.-S., Duff, Jordanou, M.: JESSICA for Smart and Sustainable Cities, European Investment Bank, Mazars LLP. London (2012)

35. Angelidou, M.: Smart city policies: A spatial approach. Cities, 41, S3-S11 (2014)

36. Andreani, S., Kalchschmidt, M., Pinto, R., \& Sayegh, A.: Reframing technologically enhanced urban scenarios: A design research model towards human centered smart cities. Technological Forecasting \& Social Change, 142, 15-25 (2019)

37. Schaffers, H., Komninos, N., Pallot, M., Trousse, B., Nilsson, M., Oliveira, A.: Smart cities and the future internet: Towards cooperation frameworks for open innovation. In The future internet assembly (pp. 431-446). Springer, Berlin, Heidelberg (2011)

38. Čambàl, Miloš, Cagàňovà, Dagmar: Corporate Culture Influence on Effective Initialization and Application of Knowledge Management in Enterprises. In Proceedings of 11th European Conference on Knowledge Management (ECKM 2010) : Universidade Lusíada de Vila Nova de Famalicao, Portugal, 2-3 September 2010. Famalicao: Academic Publishing International, 2010, s.176-181. ISBN 978-1-906638-71-9. In database WOS and SCOPUS

39. Meijer, A.J., Thaens, M.: Urban Technological Innovation: Developing and Testing a Sociotechnical Framework for Studying Smart City Projects. Urban Affairs Review, 54(2), 363-387 (2018)

40. Angelidou, M.: The Role of Smart City Characteristics in the Plans of Fifteen Cities. Journal of Urban Technology, 24(4), 3-28 (2017)

41. Ardito, L., Ferraris, A., Petruzzelli, A. M., Bresciani, S., Del Giudice, M.: The role of universities in the knowledge management of smart city projects. Technological Forecasting and Social Change, 142, 312-321 (2019)

42. Engelbert, J., van Zoone, L., Hirzalla, F.: Excluding citizens from the European smart city: The discourse practices of pursuing and granting smartness. Technological Forecasting \& Social Change, 142, 347-353 (2019)

43. Allam, Z., Newman, P.: Redefining the Smart City: Culture, Metabolism and Governance. Smart Cities, 1(1), 4-25 (2018) 